\title{
Preterm Infant with a Catastrophic Hemorrhagic-Thromboembolic Incident
}

\author{
Adel E. Abdelhamid \\ Rosie Hospital, Cambridge University Hospitals, Cambridge, UK
}

\section{Established Facts}

- Neonates are at increased risk for thrombosis; in part, pregnancy is a prothrombotic condition, and plasma concentrations of factors involved in coagulation and fibrinolysis differ significantly compared to children and adults.

- Thrombophilic disorders, known to be multigenic, may be phenotypically expressed in different perinatal and neonatal thrombotic syndromes that may lead to lifelong disability.

- An association between thromboembolic/hemorrhagic brain diseases in the newborn and both factor $\mathrm{V}_{\text {Leiden }}$ and prothrombin G20210A mutations has been recognized.

\section{Novel Insights}

- Disseminated intravascular coagulopathy, representing the extreme stage of thrombohemorrhagic conditions, may be secondary to a prothrombotic disorder of combined heterozygosity.

- Neonatal thrombotic risk in response to a paternal or combined parental disorder may be underreported, with the focus being on mothers during pregnancy.

- Neonates with significant/widespread disseminated intravascular coagulopathy but no clear cause may be candidates for thrombophilia screening.

\section{Key Words}

Preterm infant $\cdot$ Neonate $\cdot$ Thrombosis $\cdot$ Embolism .

Bleeding $\cdot$ Coagulopathy $\cdot$ Stroke

\section{Abstract \\ Thrombotic disease of the newborn is uncommon but usu- ally associated with serious morbidity and mortality. Al- though the operating mechanisms of coagulation and fibri- nolysis are the same in all age groups, plasma concentrations}

of the two systems' components are significantly different in neonates compared to children and adults. This places neonates at greater risk for thrombosis that may rise considerably if a predisposing factor is present or a genetic or medical condition predisposing to thrombosis coexists. While marginal, the possibility of abnormal bleeding secondary to congenital prothrombotic disorders has been described. A significant association between thromboembolic/hemorrhagic disease in newborns and each of factor $V_{\text {Leiden }}$ and prothrombin G20210A mutations has been reported. Al-

\section{KARGER}

Fax +4161306 1234

E-Mail karger@karger.ch

www.karger.com
(C) 2012 S. Karger AG, Basel

$1661-7800 / 12 / 1024-0293 \$ 38.00 / 0$

Accessible online at:

www.karger.com/neo
Dr. Adel E. Abdelhamid

Rosie Hospital, Cambridge University Hospitals

Hills Road

Cambridge CB2 0SW (UK)

Tel. +44 7739017 470, E-Mail dkishot@ doctors.net.uk 
though not a frequent occurrence in adults and children, congenital 'multigenic' thrombophilia is well known. However, the combined heterozygote state of both mutations is perhaps underreported in preterm infants. We present a severely intrauterine growth-restricted preterm baby born to consanguineous parents. He had stroke as part of a generalized bleeding-thromboembolic incident caused by combined heterozygote mutation of factor $V_{\text {Leiden }}$ and prothrombin G20210A, each of which was then found in a heterozygote form in each of the 2 parents.

Copyright $\odot 2012$ S. Karger AG, Basel

\section{Introduction}

Both thrombin-stimulated fibrin clot formation and plasmin-induced clot lysis pathways are carefully linked and regulated [1]. As clot formation progresses, thrombin binds to thrombomodulin to activate protein $\mathrm{C}$ and stop platelet activation or fibrinogen cleavage [2]. Activated protein $\mathrm{C}$ and protein $\mathrm{S}$ inactivate prothrombinase and intrinsic X-ase, respectively [3].

Thrombophilia is the term used to describe a group of inherited conditions associated with increased, and often recurrent, tendency for venous and/or arterial thromboembolism [4].

Thrombophilia is a 'multigenic' disorder that represents an interaction between the collective effects of the genotype at one or multiple loci either to raise or to lower susceptibility to disease, combined with a variety of environmental exposures that may trigger, accelerate, exacerbate or protect against the disease process [5].

A crucial element for successful gestation is the healthy growth and development of the placental vasculature. The uteroplacental interface receives almost $20 \%$ of maternal cardiac output. This initiates a self-protective physiologic adaptation in the form of increased 'thrombogenicity' at the interface. If the mother has a thrombotic tendency, the placenta may develop an unduly thrombogenic microenvironment [6].

In addition to the higher risk of placental thrombotic vasculopathy resulting in such complications as pregnancy loss, intrauterine growth restriction (IUGR), preeclampsia and placental abruption, maternal thrombophilia is also associated with a higher risk of neonatal thrombosis [7].

Neonatal thrombophilia is rare and not usually promoted by heterozygosity at a single thrombophilia locus, but rather by rare homozygous and combined heterozygous mutations of multiple genes [8].
Although all thrombophilias have been associated with neonatal thrombosis, only homozygous or compound heterozygous protein $\mathrm{C}$ and/or protein $\mathrm{S}$ deficiencies are reported as adequate to induce neonatal thrombosis [9].

Factor $\mathrm{V}_{\text {Leiden }}(\mathrm{FVL})$, attributable to a specific autosomal dominant gene mutation, is an abnormal version of factor $\mathrm{V}$ that is not susceptible to cleavage by activated protein $\mathrm{C}$ and is inactivated more slowly, resulting in a hypercoagulable state [3].

Prothrombin G20210A mutation (PGM) is another autosomal dominant mutation marked by enhanced thrombin generation leading to increased activation of thrombin-activatable fibrinolysis inhibitor, resulting in inhibition of fibrinolysis and increased thrombotic risk [8].

Each mutation predisposes patients with a heterozygous or homozygous state to a considerable risk of thromboembolism. The combined heterozygote state of both mutations in an individual may further increase this risk than each mutation alone [10].

We report on a case of an IUGR preterm infant presenting with a disseminated intravascular coagulopathy (DIC) picture of mixed thrombosis and bleeding secondary to a prothrombotic disorder of combined heterozygosity of 2 'thrombophilic' genes in accordance with history elements, supported by autopsy findings of multiorgan involvement. The parents' thrombophilia screens confirmed the heterozygote state of each, pointing to the importance of thrombophilia screening in such a context of abnormal obstetric, perinatal and neonatal history.

\section{Case Report}

An IUGR preterm male infant with a birth weight of $0.620 \mathrm{~kg}$ ( $<3$ rd centile), an occipitofrontal circumference of $22 \mathrm{~cm}(<3 \mathrm{rd}$ centile) and no dysmorphic features was born at 28 weeks' gestation to a 33-year-old, $\mathrm{G}_{4} \mathrm{P}_{0+2+1}$ Asian, rubella-immune housewife with negative hepatitis B virus and HIV serology who presented with severe preeclampsia.

Apart from 2 stillbirths at 28 and 29 weeks' gestation and an intrauterine fetal death at 33 weeks' gestation, all in rural India, no past medical or obstetric history of note was reported. Her husband is her first cousin.

On admission, she was severely hypertensive and significantly albuminuric. Following obstetric review, she was commenced on antihypertensives, moved to theatre and had an emergency cesarean section. 
Fig. 1. Cranial ultrasound scans. A large, well-defined mixed-echo area on the right side causing a midline shift to the left can be seen. It was difficult to establish if it involved the right lateral ventricle or was a large hemorrhagic parenchymal infarct.
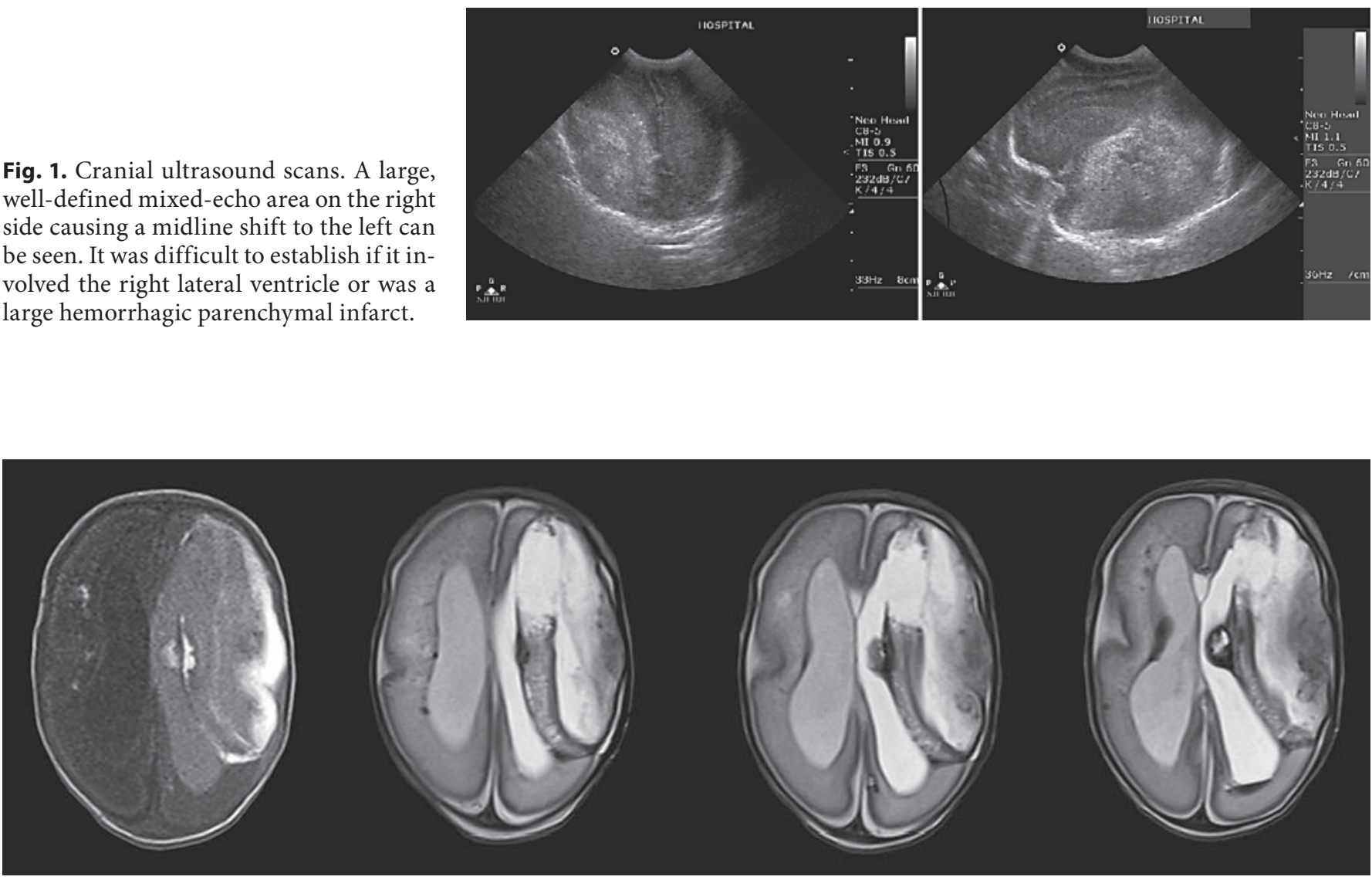

Fig. 2. Brain MRI. Extensive bleeding/infarct involving the right cortex is seen.

In view of the baby's IUGR in a context of complicated maternal history, the baby's blood was sampled for genetic testing in addition to routine investigations that were basically normal.

Immediately after admission, umbilical lines were placed but proved to be problematic over the next 2 days with frequent obstructions and ischemic changes of both lower limbs until they stopped working completely and were removed by day 3 .

An abdominal ultrasound with Doppler excluded any liver laceration, hematoma or clot formation following the line removal on days 4, 6 and 9 .

Blood film showed polychromasia, very occasional fragmented red cells and neutrophilia (corrected total white cell count of $36 \times 10^{9} / 1$, neutrophil count of $\left.32 \times 10^{9} / 1\right)$.

A cranial ultrasound scan on day 1 , and repeatedly thereafter, showed extensive periventricular flare as well as a very unusualappearing, large, well-defined, mixed-echo area in the right side causing midline shift (fig. 1). An MRI on day 11 showed an area of extensive hemorrhage/infarction involving most of the right cortex (fig. 2).

A repeat abdominal ultrasound with Doppler examination on day 11 showed a significant liver hematoma associated with increased pressure in the portal vein.
All the microbiology and virology workup showed no organism to implicate. None of the serological inflammatory markers showed any increase at any stage of the baby's life.

Following a stormy 2 -week course in the neonatal intensive care unit during which the infant remained intubated and ventilated and received multiple transfusions of different blood products for abnormal hematological parameters (table 1), he died with a devastating DIC picture.

Genetic testing of the blood sample collected on the baby's admission showed a combined heterozygote state of both FVL and PGM but an otherwise normal thrombophilia screen.

A postmortem examination (fig. 3) revealed a mixed picture of hemorrhage and thrombosis in all the solid organs examined (liver, lungs, spleen, kidney, adrenal, brain). The placenta, retrieved for examination, also displayed the same hemorrhagic/ thromboembolic pattern.

Both parents were screened for inherited thrombophilia 3-5 months after the baby's death when not showing signs of any medical illness, not on any medication, with normal blood pressure and the mother had a negative pregnancy test. Some of the screening bloods were repeated 2-3 months later for more robustness, and all the repeat results matched the original ones (table 2). 
Fig. 3. a Postmortem examination of the brain. A large infarct surrounded by hemorrhage occupied part of the right occipital, temporal and parietal lobes and affected the basal ganglia in particular. Left-side IVH with ventricular dilatation. b Postmortem examination of solid organs. (A) Lungs. Motley external surface. Congested cut surfaces with evolving bronchopulmonary dysplasia, wide interalveolar septa and fibrosis, intra-alveolar macrophages, prominent arterioles and numerous thrombi. (B) Liver. Variegated with extensive hemorrhage, extramedullary hemopoiesis and ductular proliferation. (C, D) Adrenals and spleen. Widespread congestion, hemorrhage and thrombosis. (E) Kidney. Focal interstitial hemorrhage, extramedullary hemopoiesis and eosinophilic casts in some tubules. c Placenta examination. Superficial implantation and many small infarcts consistent with maternal vascular underperfusion.
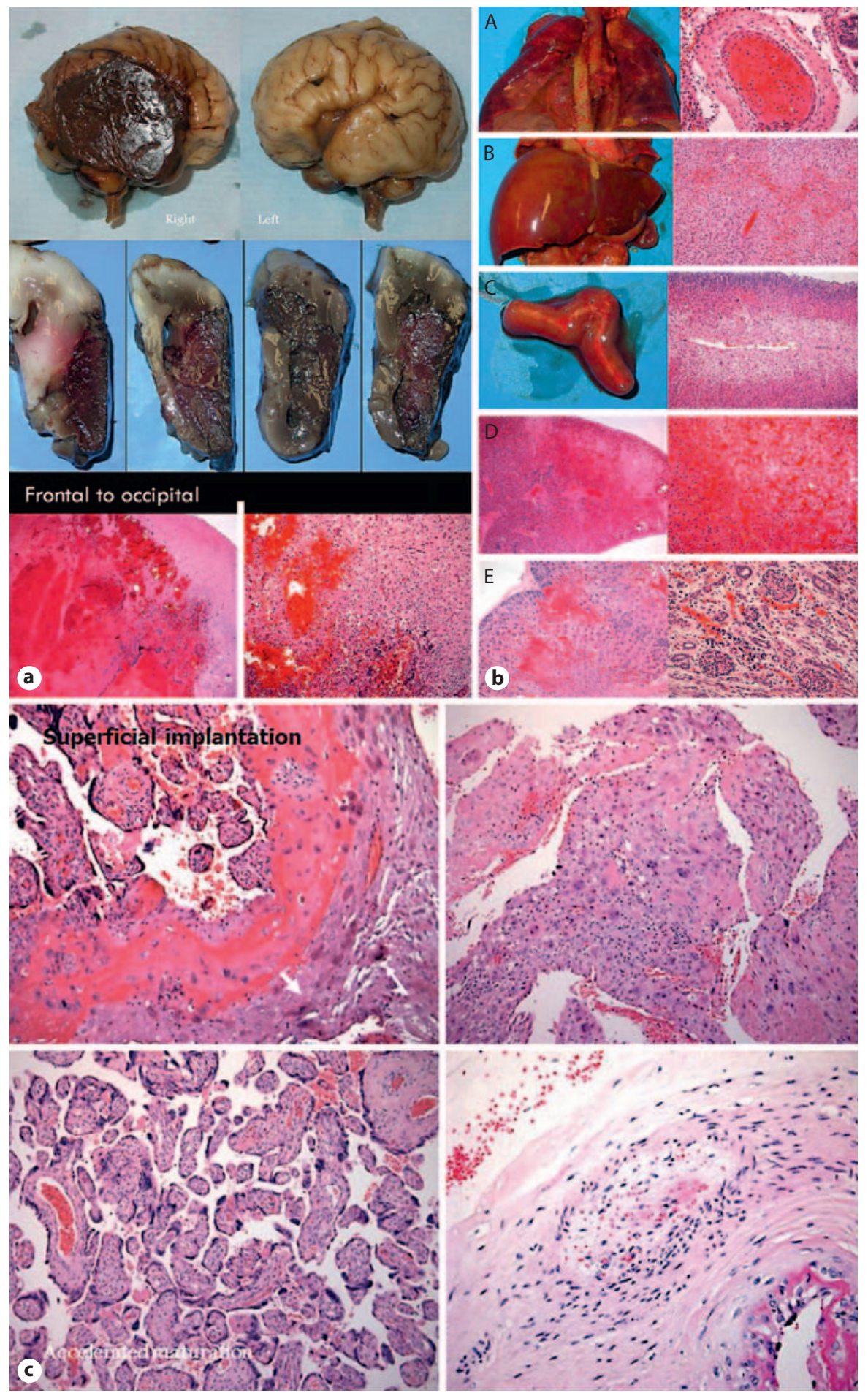

\section{Discussion}

In support to the hypothesis that thrombophilia is a 'multigenic' disorder, with varied phenotypic expressions, we present this case of an IUGR preterm infant, possibly as a consequence of maternal FVL-related pregnancy complications, born to an Asian couple that had no identifiable risk factors. The baby presented with a widespread mixed thrombohemorrhagic picture secondary to a prothrombotic disorder of combined heterozygosity of 
Table 1. Blood results and transfusion incidents in the infant

\begin{tabular}{|c|c|c|c|c|c|c|c|c|c|c|c|c|c|}
\hline & \multicolumn{13}{|l|}{ Day of life } \\
\hline $\begin{array}{l}\mathrm{Hb}, \mathrm{g} \% \\
\text { PRBC Tn }\end{array}$ & $14.2 / 14.1$ & $13.8 / 13.9$ & $14 / 11.4$ & $\begin{array}{l}15.9 / 12.9 \\
*\end{array}$ & $\begin{array}{l}13 \\
*\end{array}$ & $\begin{array}{l}\text { 13.4/14.9/13.8 } \\
*\end{array}$ & $17.1 / 13.5$ & 14.1 & $\begin{array}{l}14.4 / 13.9 \\
*\end{array}$ & $\begin{array}{l}11.5 \\
*\end{array}$ & 15.9 & $\begin{array}{l}15 / 11.5 \\
*\end{array}$ & $\begin{array}{l}15.7 \\
*\end{array}$ \\
\hline $\begin{array}{l}\text { Platelet count, } \times 10^{9} / 1 \\
\text { Platelet Tn }\end{array}$ & $140 / 148$ & $191 / 163$ & $143 / 153$ & $107 / 71$ & $\begin{array}{l}25 \\
*\end{array}$ & $\begin{array}{l}19 / 110 / 121 \\
*\end{array}$ & $\begin{array}{l}167 / 126 \\
*\end{array}$ & 39 & $\begin{array}{l}67 / 48 \\
*\end{array}$ & 249 & 114 & $\begin{array}{l}52 / 19 \\
*\end{array}$ & 52 \\
\hline PT, s & 13 & $12.4 / 12.1$ & 12.7 & 18.5 & 22 & 24.8 & 24.6 & 18.3 & 18.3 & 14.1 & & 19.4 & 20.9 \\
\hline Fibrinogen, s & 2 & $2.3 / 2.1$ & 2.2 & 1 & 1.1 & 1 & 1.1 & 1.1 & 0.9 & 1.5 & & 0.9 & 1.3 \\
\hline FFP Tn & & & & & $*$ & * & $*$ & & $*$ & & & $* *$ & * \\
\hline
\end{tabular}

$\mathrm{Hb}=$ Hemoglobin; $\mathrm{PRBC}=$ packed red blood cell; $\mathrm{Tn}=$ transfusion; $\mathrm{PT}=$ prothrombin time; APTT = activated partial thromboplastin time; INR = international normalized ratio; FFP $=$ fresh frozen plasma.

* Transfusion given.

2 'thrombophilic' genes, each subsequently found in one of the parents.

Although it is not the first reported case of neonatal thrombophilia associated with combined heterozygosity, it highlights areas in practice that may be overlooked in the management of familial, maternal and neonatal thromboembolic and hemorrhagic diseases in relation to prematurity.

Moreover, a relatively early-onset, possibly antenatal, extensive bleed associated with a big hemorrhagic parenchymal infarct in a 28 -week preterm infant, in the context of DIC, would arguably need more than routine investigation.

This case indicates a higher risk of thrombosis/bleeding in preterm patients with a combined heterozygous defect, who are more prone to 'atypical' thrombosis/ bleeding, especially intracranial.

As thrombosis/bleeding plus two thrombophilic mutations is perhaps a rare incident, the different presentations and risks need to be defined and addressed as more cases are identified.

Neonatal thrombophilia presents in different ways and involves different organ systems, especially the brain, resulting in neonatal stroke, central venous thrombosis and porencephaly, alongside such manifestations as purpura fulminans and renal vein thrombosis [9].

In addition to these common thromboembolic manifestations, fibrinolytic system disorders can also present with abnormal bleeding [11], which might have been responsible for, or at least contributory to, the DIC picture in our case.

Although underestimated, being masked by other pathologies known to present in preterm newborns, and not fully addressed in some ethnicities, the incidence of pediatric thrombosis is the highest among neonates [8]. However, preterm babies represent a unique group in that the relatively frequent occurrence of intraventricular hemorrhage (IVH) usually masks the incidence of large venous thrombi or arterial stroke.

The mixed thrombotic-hemorrhagic state of DIC and IVH is not a rare incident in sick preterm neonates. The multifactorial etiology of the two conditions may involve coagulation/fibrinolysis disturbances and venous infarction, and many fibrinolytic system disorders, including FVL and PGM, have been found more commonly in preterm infants with IVH than in the general population. However, they are usually attributed to other pathologies. This may reflect not only the complexity of the disease processes and the multiplicity of risk factors involved, but also the subtle nature of clinical signs, lack of awareness or difficulties obtaining the necessary diagnostic tests.

Neonatal thrombophilia seems to be associated with multiple risk factors [12]. In the present case, apart from umbilical lines and perhaps cesarean section, risk factors such as infection, dehydration, congenital heart disease or polycythemia were systematically ruled out.

Evidence has pointed to maternal thrombophilic disorders as a cause of antenatal/neonatal thromboembolic manifestations [13]. However, neonatal thrombotic risk in response to a paternal or combined parental disorder is underreported.

The extent of the contribution of the father's PGM and other risk factors to our baby's DIC remains questionable. Data on the relation between maternal PGM and obstetric complications are very controversial. Few reports have 
Table 2. Blood count, clotting and thrombophilia screening results in the infant's parents

\begin{tabular}{|c|c|c|c|}
\hline & Father & Mother & $\begin{array}{l}\text { Adult } \\
\text { reference } \\
\text { range }\end{array}$ \\
\hline \multicolumn{4}{|l|}{ Complete blood count } \\
\hline $\begin{array}{l}\mathrm{Hb}, \mathrm{g} \% \\
\text { Platelet count }\end{array}$ & 13.3 & 10.6 & $13-17$ \\
\hline$\times 10^{9} / 1$ & 338 & 549 & $150-450$ \\
\hline \multicolumn{4}{|l|}{ Clotting } \\
\hline PT, s & 10.5 & 11 & $12-14$ \\
\hline APTT, s & 22 & 27 & $23-38$ \\
\hline TT, s & 10.3 & 11.1 & \\
\hline Fibrinogen, g/l & 3.5 & 3.4 & $2-4$ \\
\hline FVL mutation & negative & heterozygote & negative \\
\hline PGM & heterozygote & negative & negative \\
\hline Protein C activity, \% & 78 & 71 & $70-140$ \\
\hline Activated protein $C$ & & & \\
\hline resistance ratio & $<2$ & 2 & $<2$ \\
\hline \multicolumn{4}{|l|}{ Protein S } \\
\hline Total, g/l & 73 & 66 & $65-85$ \\
\hline Activity, \% & 76 & 72 & $70-140$ \\
\hline \multicolumn{4}{|l|}{ Antithrombin } \\
\hline Activity, \% & 81 & 103 & $80-120$ \\
\hline Antigen, g/l & 2.4 & 3 & $2-4$ \\
\hline \multicolumn{4}{|l|}{ Fasting plasma homo- } \\
\hline cysteine, $\mu \mathrm{mol} / \mathrm{l}$ & 8 & 7 & $<18$ \\
\hline Lipoprotein(a), mg/dl & 10 & 13 & $<30$ \\
\hline Factor VIII, \% & 115 & 142 & $70-150$ \\
\hline Anticardiolipin & & & $0-25$ \\
\hline $\mathrm{IgG}, \mathrm{U} / \mathrm{ml}$ & 11 & 9 & \\
\hline \multicolumn{4}{|l|}{ Anticardiolipin } \\
\hline $\mathrm{IgM}, \mathrm{U} / \mathrm{ml}$ & 12 & 14 & $0-25$ \\
\hline Lupus anticoagulant & negative & negative & negative \\
\hline \multicolumn{4}{|l|}{ Anti- $\beta_{2}$ glycoprotein-I } \\
\hline $\mathrm{IgG}, \mathrm{U} / \mathrm{ml}$ & 1 & 3 & $<10$ \\
\hline Anti- $\beta_{2}$ glycoprotein-I & & & \\
\hline $\mathrm{IgM}, \mathrm{U} / \mathrm{ml}$ & 1 & 2 & $<10$ \\
\hline
\end{tabular}

$\mathrm{Hb}=$ Hemoglobin $; \mathrm{PT}=$ prothrombin time; $\mathrm{APTT}=$ activated partial thromboplastin time; $\mathrm{TT}=$ thrombin time.

related PGM to cerebrovenous thrombosis in newborns $[14,15]$.

Consanguinity may indicate a homozygous disorder; however, in our case, the combined heterozygote state is perhaps unusual unless the family has both defects or one or both of the mutations are de novo.

Cases of thromboembolism associated with homozygous FVL or PGM in children and newborns are quite rare and even rarer for the combined heterozygote mutations. In adults and children, however, congenital 'multi- genic' thrombophilia is well reported, but not as a frequent occurrence [16].

Although the clinical implications of such an occurrence are not fully established, the risk for spontaneous and recurrent venous thromboembolism with FVL and PGM is significantly higher compared to that with either gene alone. This association was even more noticeable in females, indicating that the combined mutation defect may be more serious, perhaps requiring a different preventive and therapeutic approach, especially in pregnant women [17].

While more common thrombophilias, including FVL and PGM, are associated with a lower thrombosis risk than the less common ones (antithrombin III, protein C, protein $\mathrm{S}$ deficiency), the risk is 5-10 times higher in FVL heterozygotes than in normal individuals and 50-100 times higher in homozygotes than in normal individuals [9].

The incidence of thrombosis in pregnancy among patients with FVL is estimated to be around $17 \%$. The prothrombotic effect of the FVL mutation may be further compounded by the 'physiological' progressive decrease in activated protein C during pregnancy [18].

Moreover, pregnant women with the FVL mutation can develop placental thrombosis and, in turn, complications associated with placental hypoxia such as preeclampsia, placental abruption, IUGR, stillbirth and miscarriage which necessitate anticoagulant therapy [19].

Both FVL and PGM are autosomal dominant traits. It is difficult to estimate the risk of clinical thrombosis in a given individual with one or both mutations, especially if heterozygote. This may be attributed to the variable penetrance, polymorphism and/or degree of exposure to other risk factors [16]. In the present case, each of the parents was heterozygote for one mutation, but neither had a clear family or personal history of thromboembolism. However, the mother presented a full-blown picture of thrombophilia-associated complications of pregnancy, with a bad obstetric history that may be explained by the high risk of recurrence.

Possible explanations of this phenomenon could be 'gene/gene interaction', i.e. when two or more different genes influence the outcome of a single trait, a 'double hit' mechanism, i.e. where the phenotype results from the accumulating influence of different mutations, with one priming the cell for the effect of the other(s), or polymorphism maintained by selection favoring the heterozygote [20]. 


\section{Conclusion}

Given the frequency of the 2 mutations FVL and PGM, a pregnant woman who presents with either a family, personal or obstetric history suggestive of thrombophilia should undergo testing to ensure proper risk stratification and therapeutic management.

A complete laboratory evaluation for these disorders, for both the mother and baby, is indicated in cases of neonatal stroke, central venous thrombosis and late fetal loss.

Congenital thrombophilia should be considered in patients with spontaneous or extensive thrombosis, ischemic skin lesions or purpura fulminans or a family history of purpura fulminans.
However, IVH, especially if atypical, is another candidate for the list of disease states that may be triggered by thrombophilic coagulation abnormalities including FVL, especially in such a context of a complicated obstetric history.

\section{Disclosure Statement}

The author has no conflicts of interest or financial disclosures to report.

\section{References}

$>1$ Binette TM, Taylor FB, Peer G, Bajzar L: Thrombin-thrombomodulin connects coagulation and fibrinolysis: more than an in vitro phenomenon. Blood 2007;110:3168-3175.

$\checkmark 2$ Perrotta PL, Svensson AM: Molecular diagnostics in hemostatic disorders. Clin Lab Med 2009;28:367-390.

>3 Kenet G, Chan AK, Soucie JM, Kulkarni R: Bleeding disorders in neonates. Haemophilia 2010;16(suppl 5):168-175.

$\checkmark 4$ Remkova A: Diagnostic approach to hypercoagulable states. Bratisl Lek Listy 2006;107: 292-295.

5 Carbone JF, Rampersad R: Prenatal screening for thrombophilias: indications and controversies. Clin Lab Med 2010;30:747-760.

6 Rizack T, Rosene-Montella K: Special hematologic issues in the pregnant patient. Hematol Oncol Clin North Am 2012;26:409-432.

7 Verspyck E, Borg J-Y, Roman H, Thobois B, Pia P, Marpeau L: Hereditary thrombophilia and recurrence of ischemic placental disease. Am J Obstet Gynecol 2010;202:54.e1-54.e5.

$>8$ Demirel N, Aydin M, Zenciroglu A, Bas AY, Yarali N, Okumus N, Cinar G, Ipek MS: Neonatal thrombo-embolism: risk factors, clinical features and outcome. Ann Trop Paediatr 2009;29:271-279.

-9 Saxonhouse MA, Burchfield DJ: The evaluation and management of postnatal thrombosis. J Perinatol 2009;29:467-478.
10 Laugesaar R, Kahre T, Kolk A, Uustalu U, Kool P, Talvik T: Factor V Leiden and prothrombin G20210A mutation and paediatric ischaemic stroke: a case-control study and two meta-analyses. Acta Pediatr 2010;99: 1168-1174.

11 Witmer C, Ichord R: Crossing the bloodbrain barrier: clinical interactions between neurologists and hematologists in pediatrics - advances in childhood arterial ischemic stroke and cerebral venous thrombosis. Curr Opin Pediatr 2010;22:20-27.

12 Armstrong-Wells J, Johnston SC, Wu YW, Sidney S, Fullerton HJ: Prevalence and predictors of perinatal hemorrhagic stroke: results from the Kaiser Pediatric Stroke Study. Pediatrics 2009;123:823-828.

13 Curry CJ, Bhullar S, Holmes J, Delozier CD, Roeder ER, Hutchison HT: Risk factors for perinatal arterial stroke: a study of 60 mother-child pairs. Pediatr Neurol 2007;37:99107.

14 Dewey FE, Chen R, Cordero SP, Ormond KE, Caleshu C, Karczewski KJ, Whirl-Carrillo M, Wheeler MT, Dudley JT, Byrnes JK, Cornejo OE, Knowles JW, Woon M, Sangkuhl K, Gong L, Thorn CF, Hebert JM, Capriotti E, David SP, Pavlovic A, West A, Thakuria JV, Ball MP, Zaranek AW, Rehm HL, Church GM, West JS, Bustamante CD, Snyder M, Altman RB, Klein TE, Butte AJ, Ashley EA: Phased whole-genome genetic risk in a family quartet using a major allele reference sequence. PLoS Genet 2011; 7:e1002280.
15 Rodger MA, Betancourt MT, Clark P, Lindqvist PG, Dizon-Townson D, Said J, Seligsohn U, Carrier M, Salomon O, Greer IA: The association of factor $\mathrm{V}$ Leiden and prothrombin gene mutation and placentamediated pregnancy complications: a systematic review and meta-analysis of prospective cohort studies. PLoS Med 2010; 7:e1000292.

16 Bradley LA, Palomaki GE, Bienstock J, Varga E, Scott JA: Can factor V Leiden and prothrombin G20210A testing in women with recurrent pregnancy loss result in improved pregnancy outcomes?: results from a targeted evidence-based review. Genet Med 2012; 14:39-50

17 DeSancho MT, Berlus N, Christos PJ, Rand J: Risk factors for clinical manifestations in carriers of factor V Leiden and prothrombin gene mutations. Blood Coagul Fibrinolysis 2010;21:11-15.

18 James AH: Pregnancy and thrombotic risk. Crit Care Med 2010;38:S57-S63.

19 Kjellberg U, van Rooijen M, Bremme K, Hellgren M: Factor V Leiden mutation and pregnancy-related complications. Am J Obstet Gynecol 2010;203:469.e1-e8.

-20 Hartel C, Konig I, Koster S, Kattner E, Kuhls E, Kuster H, Moller J, Muller D, Kribs A, Segerer H, Wieg C, Herting E, Gopel W: Genetic polymorphisms of hemostasis genes and primary outcome of very low birth weight infants. Pediatrics 2006;118:683-689. 